\title{
Modelagem da qualidade da água em sistemas de macrodrenagem de bacias urbanas
}

\author{
Water quality modeling in urban basins macrodrainage systems
}

\begin{abstract}
Sinara Martins Camelo ${ }^{1 *} \odot$, Mônica de Amorim Coura ${ }^{2} \oplus$, Andréa Carla Lima Rodrigues ${ }^{2} \odot$, Rui de Oliveira $^{3} \odot$, Francisco das Chagas da Costa Filho ${ }^{4} \odot$, Iana Chaiene de Araujo Vidal ${ }^{5} \odot$
\end{abstract}

\section{RESUMO}

A remoção da cobertura vegetal e a impermeabilização de grandes áreas somadas à ineficiência dos serviços básicos de saneamento, contribuem para o aumento das cargas poluidoras pontuais e difusas que são transportadas superficialmente pelas águas pluviais, causando impactos negativos ao sistema de drenagem. Como o despejo ilegal de efluentes domésticos em redes de drenageméuma realidade observada em todo o país, principalmente no meio urbano, hoje, a maior preocupação dos gestores e estudiosos é voltada às fontes pontuais de poluição e, apesar da importância, as fontes difusas têm recebido pouca atenção. Este trabalho objetivou modelar, utilizando o programa Storm Water Management Model (SWMM), a qualidade das águas pluviais a partir da avaliação do acúmulo de poluentes na superfície do solo em períodos secos e da lavagem durante eventos de precipitação na Bacia Hidrográfica Riacho do Prado, inserida no perímetro urbano da cidade de Campina Grande, Paraíba. Oito pontos no canal de drenagem foram monitorados, analisando-se as variáveis demanda bioquímica de oxigênio (DBO), demanda química de oxigênio (DQO) e fósforo total (FT), além da determinação da vazão. Os resultados obtidos nas simulações do comportamento dos poluentes em escala temporal para o evento medido do dia 08 de junho de 2018 foram condizentes com os valores observados nas análises laboratoriais, confirmando a eficiência dos resultados para as outras simulações realizadas. Os dias antecedentes sem chuva e a intensidade da precipitação se mostraram importantes na análise da carga poluente.

Palavras-chave: simulação qualitativa; canais pluviais; Storm Water Management Model.

\begin{abstract}
Removal of vegetation cover and the expansion of impermeable land, together with the inefficiency of basic sanitation services, contribute to the increase of point and diffuse pollutant loads drained by rainwater, causing negative impacts at drainage system. As the illegal discharging of domestic sewage in drainage canals is a reality observed throughout the country, especially in urban areas, today the main concern of managers and researchers is directed to the point sources of pollution and, despite the importance, diffuse sources have received little attention. This work aims to model the rainwater quality using the Storm Water Management Model (SWMM) from the evaluation of buildup pollutants on the soil surface in dry periods and the washoff during precipitation events in the Riacho do Prado watershed located in the urban area of Campina Grande, Paraíba. Eight points were monitored at the drainage canal, in which the variables $\mathrm{BOD}_{5}, \mathrm{COD}$, and total phosphorus were analyzed, in addition to flow determination. The results obtained on the simulations of behavior of pollutants in time scale for the actual event of 06/08/2018 were in agreement with the values observed at laboratory analyses, confirming the efficiency of results for the other simulations. The previous days without rain and the intensity of precipitation were important in the analysis of the pollutant load.
\end{abstract}

Keywords: quality of drainage water; mathematical modeling; Storm Water Management Model.

\section{INTRODUÇÃO}

O Decreto $n^{\circ} 7.217 / 2010$ (BRASIL, 2010), regulamentador da Lei $\mathrm{n}^{\circ}$ 11.445/2007 de saneamento básico no Brasil, estabelece que, assim com os outros serviços públicos de saneamento, o manejo de águas pluviais deve ser realizado de forma adequada à saúde pública e à proteção do meio ambiente e deve possuir infraestrutura exclusiva e independente. Entretanto, na maioria das cidades brasileiras ainda se observa o lançamento de esgotos sanitários em canais de drenagem. Tais lançamentos comprometem a qualidade das águas pluviais gerando risco à saúde da população e impactos ambientais graves.

'Programa de Pós-Graduação em Ciência e Tecnologia Ambiental, Doutorado em Engenharia Ambiental, Universidade Estadual da Paraíba - Campina Grande (PB), Brasil. 2Departamento de Engenharia Civil, Programa de Pós-Graduação em Engenharia Civil e Ambiental, Universidade Federal de Campina Grande - Campina Grande (PB), Brasil. 32Departamento de Engenharia Sanitária e Ambiental, Programa de Pós-Graduação em Ciência e Tecnologia Ambiental, Universidade Estadual da Paraíba - Campina Grande (PB), Brasil. ${ }^{4}$ Programa de Pós-Graduação em Engenharia Civil e Ambiental, Universidade Federal de Campina Grande - Campina Grande (PB), Brasil.

${ }^{5}$ Programa de Pós-Graduação em Engenharia Civil e Ambiental, Universidade Federal da Paraíba - João Pessoa (PB), Brasil.

*Autor correspondente: sinara_@hotmail.com

Recebido: 08/02/2019 - Aceito: 06/09/2019 - Reg. Abes: 20190033 
Assim como a poluição pontual ocasionada por esgotos clandestinos, a poluição difusa advinda das chuvas e dos escoamentos superficiais contribui como uma importante fonte de deterioração da qualidade da água de drenagem urbana (SONG et al., 2017). Esse tipo de despejo, ao contrário dos lançamentos pontuais, é um fenômeno aleatório de difícil mensuração.

Ferreira (2008) constatou que a concentração de poluentes ao longo do tempo, associada a um determinado evento pluviométrico, é uma informação útil para o gerenciamento da drenagem urbana, planejamento e dimensionamento de estruturas de controle de poluição. A implantação de redes de monitoramento e a aplicação de modelagem matemática têm ganhado destaque nessa questão. Ambas permitem a análise dos impactos das mudanças nas condições atuais e a modelagem permite a simulação de condições futuras e diferentes cenários (ZAFFANI, 2012).

Zhu et al. (2012) afirmam que os modelos matemáticos são essenciais para o entendimento da qualidade das águas pluviais e precisam de mais desenvolvimento. A modelagem pode ser utilizada para predição, análise e monitoramento da qualidade das águas urbanas e sua poluição, desde que haja dados suficientes. Para Tuomela, Sillanpää e Koivusalo (2019), a ausência de dados de qualidade das águas também impõe uma abordagem simplificada na modelagem.

De acordo com Petrucci et al. (2014), os modelos de águas pluviais atualmente disponíveis não são totalmente explorados para a simulação da qualidade da água. O modelo da US EPA SWMM, por exemplo, embora seja amplamente aplicado para simulações de escoamento superficial, raramente foi aplicado para avaliar as contribuições de poluentes na área de origem com análise de dados de qualidade de água no local (TUOMELA; SILLANPÄ̈̈; KOIVUSALO, 2019).

Campina Grande, cidade de médio porte do interior da Paraíba, apesar de possuir números acima da média nacional em relação ao saneamento básico, ainda apresenta, em algumas localidades, falhas no sistema de drenagem urbana principalmente em relação à contaminação das águas por fontes pontuais e difusas, com canais de drenagem visivelmente contaminados por esgotos domésticos e resíduos sólidos. Entre esses locais, a Bacia Hidrográfica Riacho do Prado é apresentada nesse documento como objeto de análise.

Diante do exposto, o presente estudo teve como objetivo modelar a qualidade das águas pluviais levando em consideração o acúmulo de poluentes durante períodos de escassez de chuva e a lavagem e o transporte desses poluentes pela chuva na Bacia Hidrográfica Riacho do Prado, inserida no perímetro urbano da cidade de Campina Grande, Paraíba.

\section{O modelo Storm Water Management Model}

No modelo Storm Water Management Model (SWMM) o sistema de drenagem é representado por meio de elementos como sub-bacias, condutos e nós, que são interligados obedecendo às cotas de nível da área representada. Segundo Rossman (2015), as sub-bacias conduzem o escoamento até um ponto de descarga. No SWMM, os condutos podem ser canais naturais ou artificiais caracterizados de acordo com o formato da seção transversal e quanto a serem abertos ou fechados. Os canais são representados graficamente por meio de nós e condutos. Os nós são posicionados no início e no fim dos elementos de condução do escoamento superficial, possibilitando a sua conexão com outros condutos ou afluentes que se somam ao canal principal.

O SWMM é utilizado para simulação da quantidade e qualidade do escoamento superficial. Tuomela, Sillanpää e Koivusalo (2019) investigaram o uso de concentrações de qualidade de água na modelagem de cargas poluidoras utilizando o referido modelo. Sólidos suspensos totais, fósforo total (FT), nitrogênio total, chumbo, cobre e zinco foram modelados baseados nas concentrações médias dos eventos (Event Mean Concentrations - EMCs) encontrados na literatura, comparando as cargas simuladas de poluentes com as cargas medidas na captação. As cargas simuladas excederam as cargas medidas, fato explicado pela falta de dados locais para as EMCs da área de origem.

Chen et al. (2018) analisaram parâmetros do modelo SWMM combinados com dados de monitoramento de campo, construíram um modelo de cálculo de carga poluente não pontual e calibraram os parâmetros correspondentes. Foram analisadas na área de investigação a carga poluidora da demanda química de oxigênio (DQO), do nitrogênio amoniacal $\left(\mathrm{NH}_{3}-\mathrm{N}\right)$ e do FT sob diferentes condições de chuva. Os valores calculados do modelo apresentaram boa concordância com os resultados reais da medida. Sob diferentes condições de chuva, o valor máximo dos poluentes apareceu nos estágios inicial e médio da chuva, enquanto diminuiu gradualmente com o aumento das chuvas.

$\mathrm{Na}$ análise da quantidade, o SWMM oferece três opções de modelo de infiltração: Equação de Horton, fórmula de Green-Ampt e o método Soil Conservation Service (SCS) utilizando o método Curva Número (CN). A equação de Horton, utilizada neste trabalho, é expressa pela Equação 1.

$f=f_{c}+\left(f_{o}+f_{c}\right) \cdot e^{-k t}$

Em que:

$\mathrm{f}=$ taxa de infiltração $(\mathrm{mm} / \mathrm{h})$;

$\mathrm{f}_{\mathrm{c}}=$ taxa de infiltração em condição de saturação $(\mathrm{mm} / \mathrm{h})$;

$\mathrm{f}_{\mathrm{o}}=$ taxa de infiltração inicial $(\mathrm{mm} / \mathrm{h})$;

$\mathrm{e}=$ exponencial;

$\mathrm{k}=$ constante determinada a partir de medições no campo $(1 / \mathrm{h})$;

$\mathrm{t}=$ tempo (horas). 
$\mathrm{Na}$ análise da qualidade, o SWMM permite avaliar o acúmulo de poluentes durante o período seco, a lavagem desses poluentes por eventos de precipitação, a redução da sua concentração em razão de unidades de tratamento e o transporte de cargas poluentes por tubulações e canais (ROSSMAN, 2015).

Os aspectos de qualidade da água são definidos pela caracterização dos poluentes e de sua área de ocorrência em duas condições distintas: - o acúmulo do poluente em ausência de chuvas, de forma que os poluentes existentes nas superfícies são continuamente depositados nesses meios, originando o que se entende por "deposição seca";

- a lavagem desses poluentes nos períodos de chuva.

A acumulação de agentes poluentes é descrita como uma massa por unidade de área. A quantidade de poluente acumulada é uma função do número de dias sem chuva antecedentes ao evento simulado e é calculado pela Função Saturação (Equação 2). Na Função Saturação, a acumulação começa de forma linear e progressivamente diminui ao longo do tempo, até alcançar um determinado valor de saturação.

$\mathrm{b}=\frac{\mathrm{C}_{1} \cdot 1}{\mathrm{C}_{2}+\mathrm{t}}$

Em que:

$\mathrm{b}=$ acúmulo;

$\mathrm{C}_{1}$ = acumulação máxima possível (massa por unidade de área);

$\mathrm{C}_{2}=$ constante de semissaturação (número de dias necessários para alcançar a metade da máxima acumulação possível);

$\mathrm{t}=$ intervalo de tempo de tempo de acúmulo, em dias.

Neste estudo, $C_{1}$ foi determinado com dados de precipitação de um evento de 10,6 mm ocorrido na área das sub-bacias e com valores médios da concentração dos poluentes, e o valor de $\mathrm{C}_{2}$ foi obtido pelo inverso do número de dias secos.

A lixiviação de agentes poluentes ocorre durante os períodos chuvosos e descreve-se pela Concentração Média do Evento (CME) (Equação 3), sendo utilizada por ser uma abordagem eficiente e de simples compreensão. A CME é um caso especial da curva de taxa de lixiviação, estabelecendo uma relação linear entre a carga lixiviada e a vazão de escoamento, em que o expoente é 1.0.

$\mathrm{W}=\mathrm{K}_{\mathrm{W}} \cdot \mathrm{Q}^{1}$

Em que:

$\mathrm{W}=$ taxa de lixiviação;

$\mathrm{K}_{\mathrm{W}}=$ concentração de poluente lixiviado em unidades de massa por volume;

Q = escoamento nas unidades definidas pelo usuário.

\section{METODOLOGIA}

\section{Área de estudo}

Campina Grande possui uma área territorial de $594,18 \mathrm{~km}^{2}$ e população estimada em 407.472 habitantes (IBGE, 2018). O município, localizado no estado da Paraíba, representa um grande e promissor polo educacional, tecnológico e econômico, com densidade demográfica de 678,10 hab./ $/ \mathrm{km}^{2}$ (SANTOS; RUFINO; BARROS FILHO, 2017).

Quanto ao sistema de drenagem, a cidade está inserida em uma área que abrange três bacias, denominadas pelo Plano Municipal de Saneamento Básico (CAMPINA GRANDE, 2015) de bacias B, C e D - Bacia do Riacho do Bodocongó, Bacia do Riacho das Piabas e Bacia do Riacho do Prado, respectivamente. A Bacia Hidrográfica Riacho do Prado (Figura 1) possui área de $24,7 \mathrm{~km}^{2}$ e perímetro de $40,2 \mathrm{~km}$, e está dividida em 13 sub-bacias (D1 a D13), compreendendo de forma total ou parcial 22 bairros da cidade. A bacia apresenta declividades inferiores a 30\% em toda sua extensão. O padrão de ocupação da área é do tipo residencial, com sua maior parte coberta por lotes construídos (TSUYUGUCHI, 2015).

O canal de drenagem inserido na área de estudo é denominado Canal do Prado. O referido canal tem início no extravasor das águas

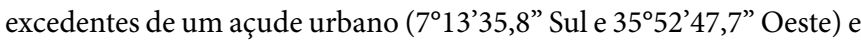
possui dois tributários que contribuem para o canal principal. Seu projeto conta com vários tipos de seção transversal, sendo elas: trapezoidal, retangular e parabólica. Após certo ponto (7¹4'47,6” Sul e 3553’22,1" Oeste) o canal deixa de ter seu revestimento artificial, seguindo seu percurso por leito natural até desaguar no Riacho Bodocongó, o qual é afluente do rio Paraíba, principal rio do estado (HENRIQUES, 2014).

\section{Monitoramento e coleta de dados}

As previsões de qualidade pelo SWMM ou qualquer outro modelo de escoamento superficial são, na maioria das vezes, hipotéticas, a menos que os dados locais para a bacia simulada estejam disponíveis para uso na calibração e na validação. Não há substituto para os dados locais (medições de chuva, vazão e concentração) com os quais calibrar e verificar as previsões de qualidade (ROSSMAN; HUBER, 2016).

Assim, para alimentar o modelo foi realizado um monitoramento da qualidade da água do Canal do Prado entre março e agosto de 2018. As amostras foram coletadas com frequência semanal em oito pontos ao longo do canal (Figura 2), sendo um ponto em cada tributário (P2 e $\mathrm{P} 4)$, três pontos ao longo do canal principal (P1, P3 e P5) e três pontos no canal após a transição do leito artificial para natural (P6, P7 e P8).

A área de contribuição para o ponto P1 é a sub-bacia D2, o ponto P2 tem sua contribuição advinda da sub-bacia D1, enquanto o ponto P3 recebe as contribuições das sub-bacias D3 e D4. O ponto P4 recebe contribuições da sub-bacia D5. O ponto P6 tem a mesma área de contribuição do ponto P5, mas se difere pelas características do canal, que 


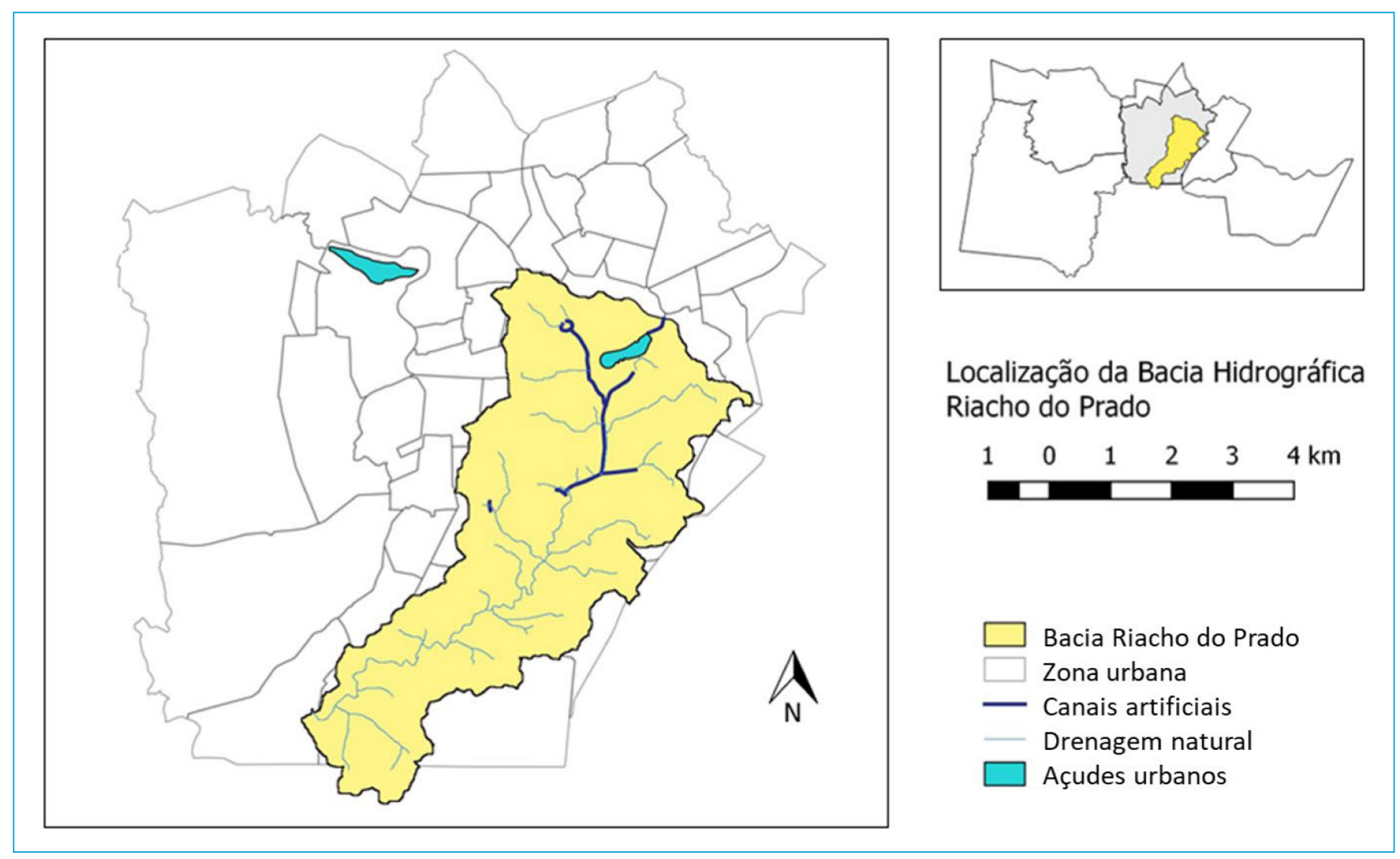

Figura 1 - Localização da Bacia Hidrográfica Riacho do Prado.

passa a ser natural. O ponto $\mathrm{P} 7$ recebe todas as contribuições advindas das sub-bacias D7, D8 e D9. Finalmente, o ponto P8 recebe as contribuições das sub-bacias D10 e D11. Por se tratar de uma área de difícil acesso, não foi possível encontrar um ponto viável de coleta para análise das contribuições das sub-bacias D12 e D13, sendo replicados os dados obtidos no ponto P8.

Diante da dificuldade de coleta dentro do canal, foi necessário o uso de um dispositivo, que consistiu em um balde acoplado a uma corda. Após a coleta, as amostras eram transferidas para recipientes plásticos com capacidade de $1.000 \mathrm{~mL}$ que, em seguida, eram acondicionadas em caixas térmicas a temperatura ambiente para serem transportadas ao laboratório.

As variáveis analisadas foram: demanda bioquímica de oxigênio (DBO), DQO e FT. Todas as variáveis foram quantificadas por métodos padronizados no Standard Methods for the Examination of Water and Wastewater (APHA; AWWA; WEF, 2012) e realizadas em triplicata. Os dados obtidos em laboratório foram utilizados como dados de entrada do modelo SWMM possibilitando, assim, que a modelagem da qualidade das águas da bacia estivesse a mais próxima possível da realidade encontrada na área e que as respostas obtidas fossem confiáveis.

De acordo com Santos (2011), a série pluviométrica no município de Campina Grande para o período de 1994 a 2009 apresentou maiores ocorrências de dias chuvosos entre os meses de abril e agosto, e as maiores ocorrências de dias secos entre os meses de outubro e dezembro. Como o período das coletas de água realizadas neste estudo foi de março a junho, meses considerados chuvosos para o município, fez-se necessária a utilização de uma metodologia para a separação dos dados em dois períodos (seco e chuvoso), para análise das cargas de poluentes nos processos de acúmulo e lixiviação.

$\mathrm{Na}$ literatura existente não há um método específico consolidado para determinar se um dia foi seco ou chuvoso. Assim, foi proposta uma metodologia baseada na afirmativa de Silva, Oliveira e Cavalcanti (1981), que consideram dia sem chuva aquele em que o índice de evapotranspiração real é maior do que o índice de chuva ocorrida nesse mesmo dia.

Cabral Júnior (2014) apresenta as médias diárias mensais da evapotranspiração de referência, em milímetros, por meio do gráfico boxplot, estimada pelo método de Penman-Monteith em Campina Grande, no período de $1^{\circ}$ de janeiro de 1977 a 31 de dezembro de 2013. Para o mês de março, os valores da evapotranspiração variaram entre 3,5 e 4,0 mm/dia. O valor de 4,0 $\mathrm{mm}$ foi escolhido como a máxima evapotranspiração diária ocorrida no mês, sendo assim considerado dia com chuva o dia em que a precipitação foi maior que $4 \mathrm{~mm}$. A análise para os meses de abril, maio, junho e julho foi feita de modo análogo. Os valores considerados foram de 3,5 e 3,0 mm/dia para abril e maio, 


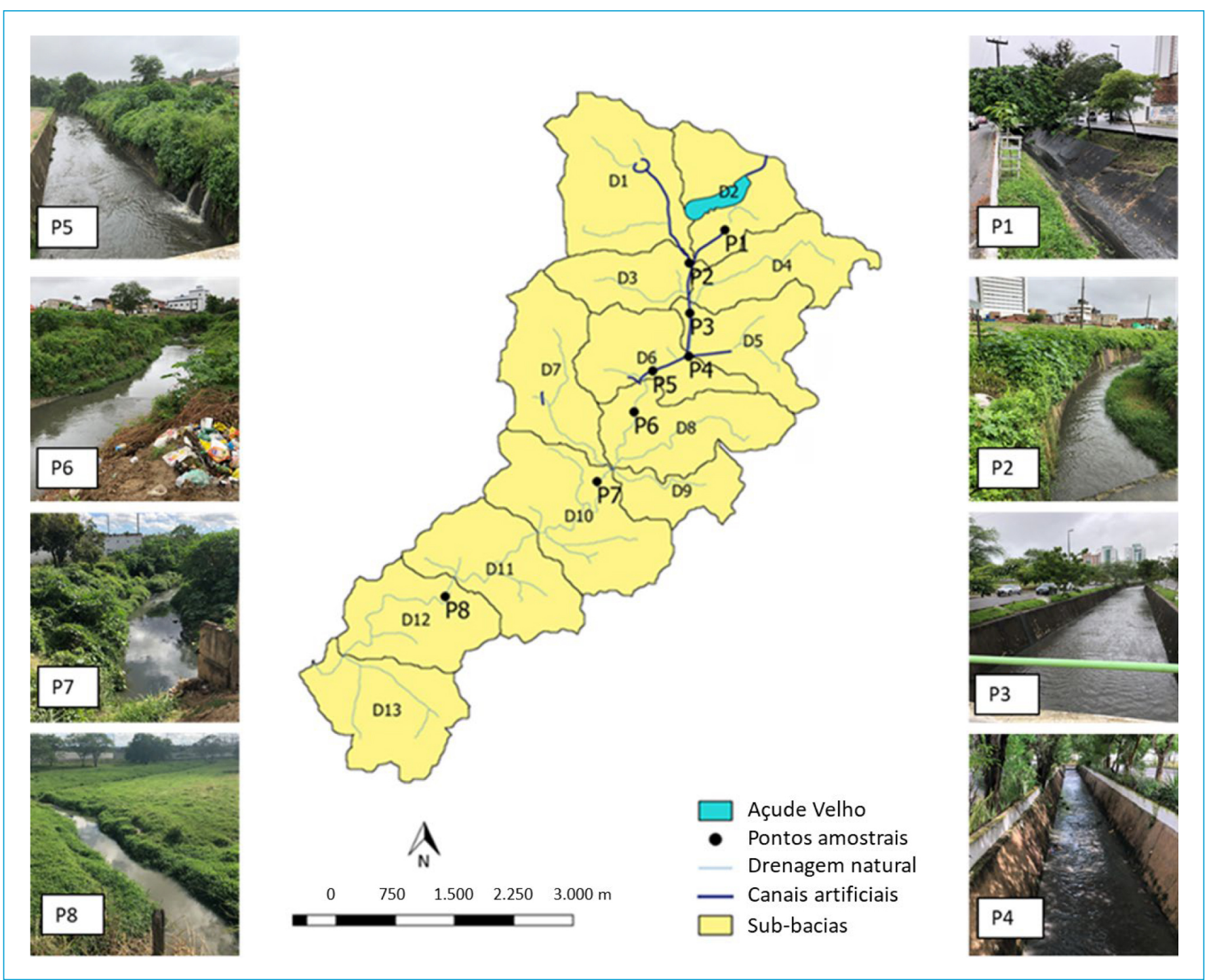

Figura 2 - Localização e representação dos pontos de coleta ao longo do canal do Prado.

respectivamente, e $2,5 \mathrm{~mm} /$ dia para junho e julho. Assim, pôde-se fazer a determinação dos dias em que foram realizadas as coletas em período chuvoso ou seco, sendo obtidos nove dias classificados como secos e 11, como chuvosos (Tabela 1).

A Tabela 1 também apresenta a precipitação acumulada nos dias anteriores à realização das coletas feitas durante o período chuvoso e que tiveram influência nos valores encontrados.

Para obter as vazões escoadas nos canais a partir dos dados de nível d'água, mediu-se a velocidade do escoamento por meio do método do flutuador. A medição da vazão foi feita nos mesmos pontos apresentados na Figura 2, e os valores obtidos se encontram na Tabela 2. Por serem áreas de difícil acesso e por não apresentarem variação significativa de vazão, não foi possível fazer a medição no ponto $\mathrm{P} 8$, e no ponto P7 conseguiu-se realizar apenas uma medição.

\section{Modelagem da qualidade da água}

A representação do sistema de drenagem no modelo SWMM é feita por meio dos elementos sub-bacias, condutos e nós. Os parâmetros necessários para a caracterização da área de estudo serão abordados com mais detalhes a seguir.

\section{Sub-bacias}

Os valores das áreas das sub-bacias, declividade e áreas impermeáveis foram calculados pelo software QGIS usando-se as shapes e o Modelo Numérico do Terreno (MNT) cedidos por Tsuyuguchi (2015) e as larguras das sub-bacias (W) definidas a partir do cálculo da largura do retângulo equivalente (le). Os coeficientes de rugosidade de Manning para superfícies impermeáveis (NI) e permeáveis (NP) utilizados foram 0,014 e 0,050, respectivamente, de acordo com o tipo de superfície de escoamento. 
Tabela 1 - Classificação das coletas em período seco e chuvoso.

\begin{tabular}{|c|c|c|c|}
\hline Dia de coleta & $\begin{array}{l}\text { Período seco } \\
\text { ou chuvoso }\end{array}$ & $\begin{array}{l}\text { Dias antecedentes } \\
\text { sem chuva }\end{array}$ & $\begin{array}{c}P_{\text {acum }} \text { nos dias } \\
\text { anteriores }(\mathrm{mm})\end{array}$ \\
\hline 14/03/2018 & Seco & 12 & - \\
\hline 22/03/2018 & Seco & 20 & - \\
\hline 28/03/2018 & Chuvoso & 2 & 6,8 \\
\hline 05/04/2018 & Seco & 6 & - \\
\hline $11 / 04 / 2018$ & Chuvoso & 3 & 14 \\
\hline 19/04/2018 & Chuvoso & 1 & 53,9 \\
\hline 25/04/2018 & Chuvoso & O & 59,5 \\
\hline O2/05/2018 & Chuvoso & 3 & 32,5 \\
\hline 10/05/2018 & Chuvoso & O & 11,1 \\
\hline $17 / 05 / 2018$ & Chuvoso & O & 11,6 \\
\hline 24/05/2018 & Chuvoso & 4 & 22,1 \\
\hline 07/06/2018 & Chuvoso & 3 & 5,6 \\
\hline 13/06/2018 & Chuvoso & 4 & 13,6 \\
\hline 21/06/2018 & Seco & 12 & - \\
\hline 28/06/2018 & Seco & 19 & - \\
\hline 05/07/2018 & Seco & 26 & - \\
\hline $12 / 07 / 2018$ & Chuvoso & O & 23,2 \\
\hline 19/07/2018 & Seco & 8 & - \\
\hline 26/07/2018 & Seco & 14 & - \\
\hline O2/08/2018 & Seco & 22 & - \\
\hline
\end{tabular}

Tabela 2 - Valores de vazão medidos.

\begin{tabular}{l|c|c|c|c}
\multirow{2}{*}{ Pontos } & \multicolumn{5}{|c}{ Vazão $\left(\mathrm{m}^{3} / \mathrm{s}\right)$} \\
\cline { 2 - 5 } P1 & 1 & 2 & 3 & 4 \\
\hline P2 & 0,063 & 0,005 & 0,01 & 0,01 \\
\hline P3 & 0,337 & 0,106 & 0,12 & 0,07 \\
\hline P4 & 0,393 & 0,140 & 0,15 & 0,18 \\
\hline P5 & 0,076 & 0,031 & 0,02 & 0,05 \\
\hline P6 & 0,678 & 0,393 & 0,19 & 0,20 \\
\hline P7 & 0,677 & 0,157 & 0,28 & 0,34 \\
\hline
\end{tabular}

Para determinar a capacidade de armazenamento em depressões em superfícies impermeáveis (DI) e permeáveis (DP) e as áreas impermeáveis não conectadas (AINC), Nóbrega (2012) calibrou o modelo considerando os intervalos sugeridos no Manual do Usuário do SWMM (ROSSMAN, 2015) e os tipos de solo predominantes na região com seus respectivos coeficientes de Manning. Foi utilizado o método de tentativa e erro, com ajuste manual dos parâmetros de entrada do programa SWMM para caracterização das sub-bacias, até chegar a um valor médio de DI e DP e AINC para aquela região (Tabela 3). Por terem sido
Tabela 3 - Valores determinados no processo de calibração.

\begin{tabular}{|c|c|c|}
\hline \multicolumn{3}{|c|}{ Parâmetros calibrados } \\
\hline (DI) & (DP) & (AINC) \\
\hline $1,91 \mathrm{~mm}$ & $5,08 \mathrm{~mm}$ & $10 \%$ \\
\hline
\end{tabular}

DI: superfícies impermeáveis; DP: superfícies permeáveis; AINC: áreas impermeáveis não conectadas.

Fonte: Nóbrega (2012)

calibrados para um bairro localizado na Bacia Hidrográfica Riacho do Prado, os valores encontrados pelo autor e apresentados na Tabela 3 foram utilizados para toda a área de estudo deste trabalho.

Os parâmetros de entrada - capacidade de infiltração inicial ( $\left.\mathrm{I}_{\mathrm{o}}\right)$, capacidade de infiltração final $\left(\mathrm{I}_{\mathrm{f}}\right)$ e constante de decaimento $(\mathrm{k})$ foram retirados de Paixão et al. (2009), que desenvolveram uma pesquisa em um município localizado a 9,4 km de distância de Campina Grande e com características geológicas e climáticas semelhantes às da área de estudo, realizando 65 testes de infiltração da água no solo, o que possibilitou a determinação da $\mathrm{I}_{\mathrm{o}}$ e da $\mathrm{I}_{\mathrm{f}}$ do solo, além da k (Tabela 4).

\section{Dados do canal}

$\mathrm{Na}$ modelagem, foram considerados somente os canais artificiais e naturais correspondentes ao sistema de macrodrenagem. As seções transversais dos canais foram retiradas do projeto do canal, digitalizadas junto à Secretaria de Planejamento, Gestão e Transparência de Campina Grande (SEPLAN) e medidas em campo. O comprimento dos condutos foi medido automaticamente pelo SWMM, a partir da inserção das coordenadas geográficas no desenho. Os valores médios de rugosidade de Manning para cada trecho dos condutos foram obtidos de Methods e Dietrich (2007) apud Tsuyuguchi (2015) e são apresentados na Tabela 5 .

\section{Dados de qualidade}

Para a realização desta análise, foram usadas neste trabalho as variáveis DBO, DQO e FT como indicadores da poluição no processo de modelagem. A Bacia Hidrográfica Riacho do Prado possui diferentes características de uso e ocupação do solo. As concentrações dos parâmetros físico-químicos da água variaram muito em todos os pontos estudados, indicando diferenças significativas nas contribuições de cada área. Por isso, os cálculos dos coeficientes utilizados nas funções de acúmulo e lavagem dos poluentes foram feitos para cada sub-bacia a partir dos valores das concentrações de DBO, DQO e FT encontradas, levando-se em consideração a contribuição de cada sub-bacia de acordo com os pontos de coleta distribuídos na área (Figura 2).

\section{Calibração e validação do modelo}

A modelagem hidráulica e hidrológica utilizando o programa computacional SWMM foi realizada na bacia de drenagem estudada. Nessa etapa, 
Tabela 4 - Valores utilizados na equação de Horton.

\begin{tabular}{|l|l|l} 
Capacidade de & Capacidade de & Constante de
\end{tabular}

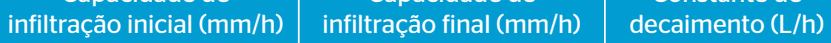

\begin{tabular}{l|l|l}
396,1 & 7,1 & 2,677 \\
\hline
\end{tabular}

Fonte: Paixão et al. (2009).

Tabela 5 - Valores do coeficiente de Manning para os canais.

\begin{tabular}{l|c} 
Trecho & Coeficiente de Manning \\
Canal do Prado & 0,016 \\
\hline Calha do riacho & 0,045 \\
\hline
\end{tabular}

Fonte: Methods e Dietrich (2007).

foram inseridas no modelo as características físicas da bacia, e ele foi calibrado para um evento específico: o dia 08 de junho de 2018, evento com um total precipitado de 10,6 mm e 15 horas de duração.

A calibração do modelo foi executada por meio de um processo iterativo. Para o caso em estudo, os resultados dos valores obtidos para os parâmetros do modelo foram alcançados manualmente por meio de um processo de tentativa e erro até que se obtivesse valores simulados compatíveis com os observados por medição. Parâmetros como largura, declividade e porcentagem de área impermeável das sub-bacias estudadas foram alterados. Apesar de serem parâmetros físicos, eles puderam ser ajustados em razão das incertezas quanto à sua determinação. Os valores dos parâmetros DI e DP foram resultados de calibrações já feitas por Nóbrega (2012), portanto não foram alterados.

Quando os valores gerados pelo SWMM atingiram, dentro de limites aceitáveis, conformações próximas aos dados observados, finalizou-se a etapa de calibração. A validação do método tem por objetivo legitimar os resultados obtidos durantes as simulações por meio da interpretação e da análise desses resultados. Para essa etapa, foram considerados o relatório de simulação e o resumo dos erros de continuidade apresentados pelo programa SWMM a cada simulação. Os erros de continuidade representam a diferença, em porcentagem, entre a quantidade armazenada incialmente, mais o fluxo que entra, e a quantidade armazenada no final, mais o fluxo que sai. De acordo com o que é estabelecido pelo modelo, se tais erros ultrapassarem o valor de $10 \%$, os resultados da simulação deverão ser questionados (ROSSMAN, 2015).

\section{Cenários simulados}

Nesta pesquisa, foram abordados os períodos hidrológicos, considerando a influência do número de dias antecedentes sem chuva no processo de acúmulo e o comportamento da lavagem dos poluentes por meio da simulação de diferentes intensidades pluviométricas.

De acordo com o organograma (Figura 3), optou-se por simular o evento medido no dia 08 de junho de 2018. Uma vez que a precipitação

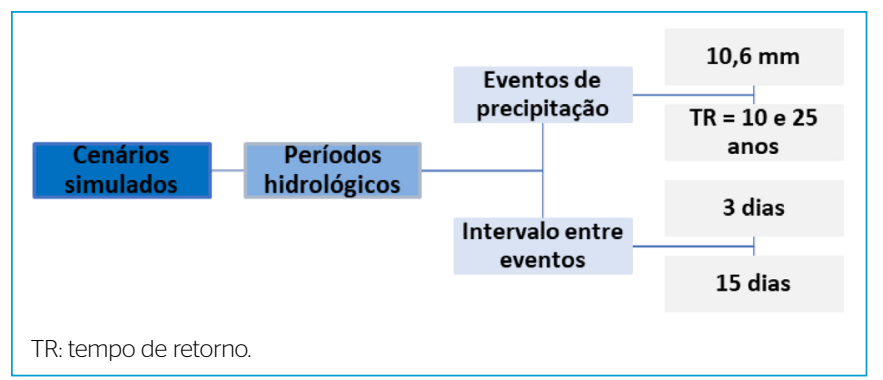

Figura 3 - Organograma dos cenários simulados.

anterior à do dia 08 de junho ocorreu no dia 04 de junho, justifica-se o período de três dias sem chuva utilizado para simulação. O número de 15 dias foi escolhido para comparação com o total acumulado para 3 dias. Para avaliar o processo de lixiviação, foram simuladas precipitações com diferentes intensidades, sendo elas a chuva ocorrida no dia 08 de junho de 2018 utilizada para calibração, e as precipitações com tempo de retorno (TR) de 10 e 25 anos, com intensidade calculada de 100,4 e 123,6 mm, respectivamente.

Para melhor apresentação dos resultados, o canal foi dividido em trechos cujos dados obtidos tiveram o mesmo comportamento (Figura 4).

A nomenclatura apresentada será utilizada na análise dos cenários propostos. Os resultados são apresentados no SWMM na forma de tabelas, gráficos ou mapas. Os mapas indicam os valores simulados por meio de uma escala de cores em que o vermelho aponta a situação mais crítica, seguido das cores amarela, verde, azul-clara e, por último, azul-escura, que indica as menores concentrações de poluentes.

\section{RESULTADOS E DISCUSSÃO}

\section{Calibração chuva versus vazão}

O resultado da simulação para o evento do dia 08 de junho de 2018 sem calibração pode ser verificado na Figura 5A. Percebe-se que os valores de chuva-vazão modelados e observados foram divergentes. A limitação nessa etapa ocorreu por não se ter acesso a um medidor de vazão automático, que permitisse a medição da vazão durante todo o evento de precipitação, para a geração do hidrograma. Assim, a calibração foi feita com apenas uma medida de vazão em determinada hora durante a ocorrência do evento chuvoso em cada ponto analisado.

Como resultado da calibração apresenta-se a Figura 5B, na qual estão plotados os gráficos da vazão observada (Qobs) juntamente com a vazão simulada (Qsim). Percebe-se que, após a calibração, houve um melhor ajuste entre os valores simulados e observados quando comparado aos resultados iniciais da Figura 5A.

O Erro Quadrático Médio (EQM) dos valores antes da calibração foi 0,19 , e após a calibração, 0,02. O valor do EQM dos dados 
calibrados foi mais próximo de zero, indicando melhor precisão dos valores simulados.

\section{Função de acúmulo de poluentes}

Os coeficientes $C_{1}$ (acumulação máxima possível - massa por unidade de área) e $\mathrm{C}_{2}$ (número de dias necessários para alcançar a metade da máxima acumulação possível) foram determinados empiricamente a partir dos dados das concentrações dos poluentes considerados na modelagem (DQO, DBO e FT) e obtidos nas análises de laboratório da água do canal no período seco (Tabela 6). Para o $\mathrm{C}_{2}$ considerou-se a média de dias secos antecedentes às 9 coletas realizadas durante esse período, que foi de 15 dias.

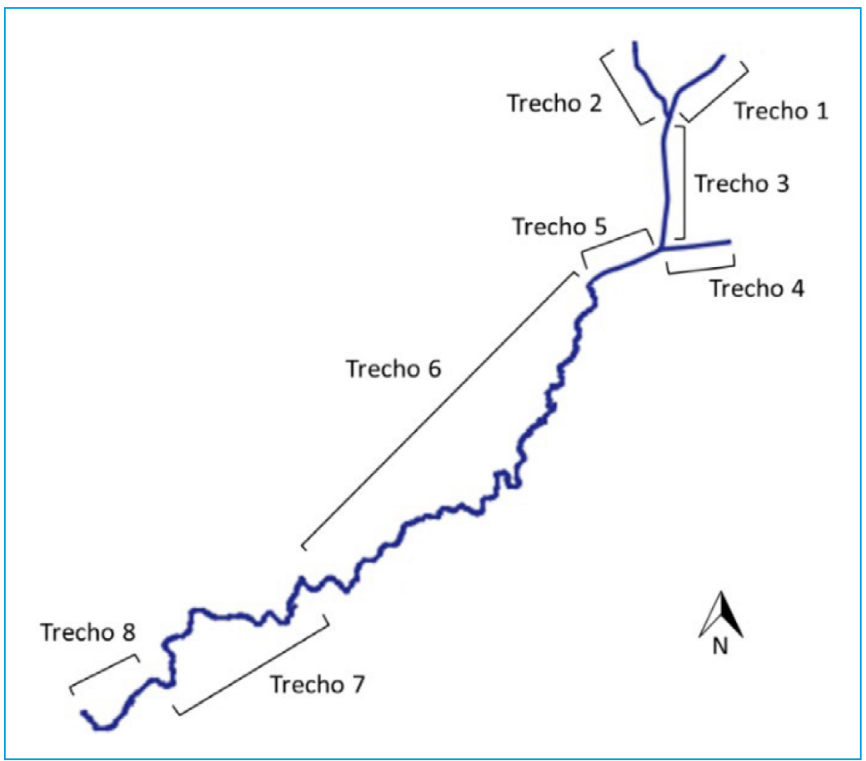

Figura 4 - Divisão do canal em trechos.
Os maiores valores de concentração de matéria orgânica e fósforo foram encontrados nas sub-bacias D1, D3, D4 e D5. Nessas sub-bacias estão localizados bairros que apresentam maior precariedade nos serviços de saneamento básico. Em decorrência disso, ocorrem nessas localidades lançamentos diretos de esgotos domésticos, efluentes de fossas sépticas e resíduos sólidos dentro dos canais de drenagem. Observa-se, por exemplo, que a quantidade de material biodegradável acumulado nas sub-bacias D3 e D4 é 66,4\% maior do que o acumulado nas sub-bacias de D10 a D13. Essa é a menor diferença entre as sub-bacias com maiores e menores concentrações de acúmulo. O mesmo comportamento é obtido para os valores de DQO e FT.

\section{Função de lavagem de poluentes}

$\mathrm{O}$ coeficiente $\mathrm{K}_{\mathrm{W}}$ (Equação 3) foi determinado por meio das amostras de água coletadas durante o período chuvoso. As concentrações médias

Tabela 6 - Valores médios de concentração de demanda bioquímica de oxigênio, demanda química de oxigênio e fósforo total (kg.ha-1).

\begin{tabular}{l|c|c|c|c}
\multirow{2}{*}{ Sub-bacias } & \multicolumn{3}{|c|}{$\mathrm{C}_{1}\left(\mathrm{~kg} \cdot \mathrm{ha}^{-1}\right)$} & \multirow{2}{*}{$\mathrm{C}_{2}$ (1.dia') } \\
\cline { 2 - 5 } D1 & DBO & DQO & FT & 0,07 \\
\hline D2 & 44,2 & 80,4 & 1,1 & 0,07 \\
\hline D3 e D4 & 10,6 & 24,7 & 0,4 & 0,07 \\
\hline D5 & 35,1 & 66,8 & 1,0 & 0,07 \\
\hline D6 & 67,7 & 107,0 & 1,4 & 0,07 \\
\hline D7 a D9 & 15,5 & 40,5 & 0,62 & 0,07 \\
\hline D10 a D13 & 15,5 & 41,9 & 0,60 & 0,07
\end{tabular}

$C_{1}$ : acumulação máxima possível (massa por unidade de área); $C_{2}$ : constante de semissaturação (número de dias necessários para alcançar a metade da máxima acumulação possível); DBO: demanda bioquímica de oxigênio; DQO: demanda química de oxigênio; FT: fósforo total.

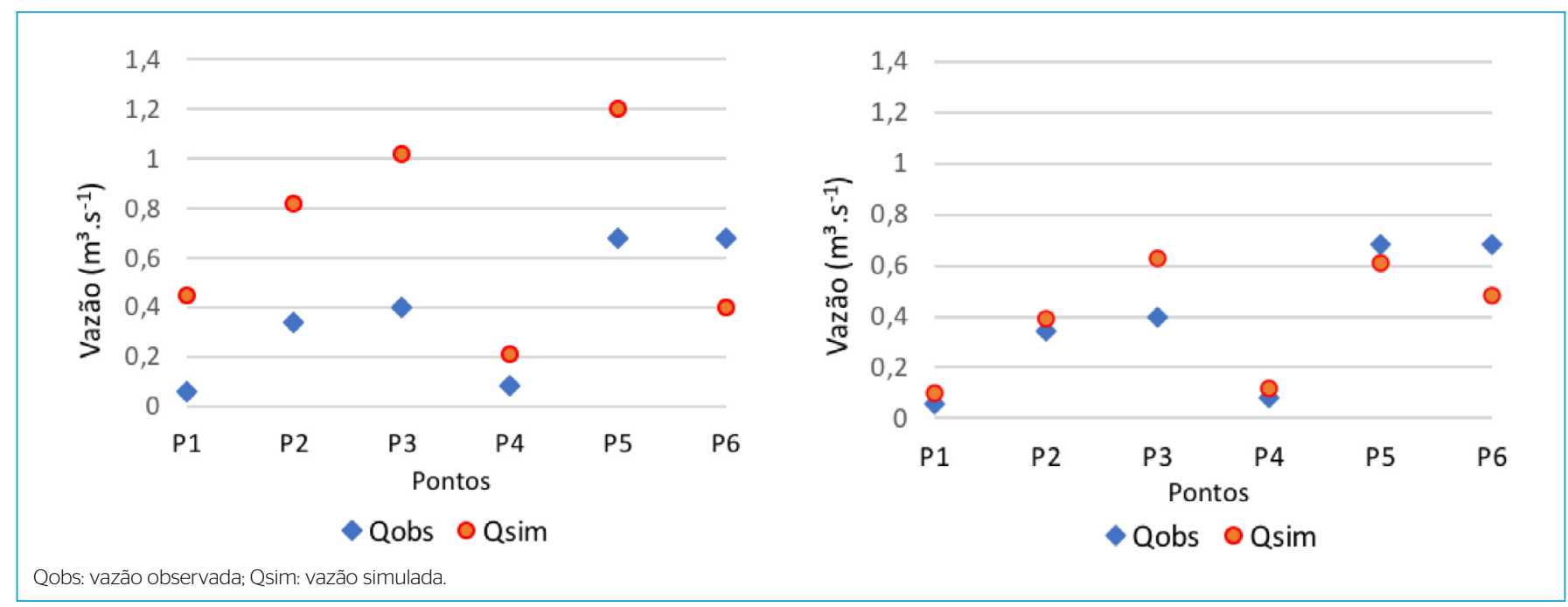

Figura 5 - Qobs versus Qsim (A) antes da calibração; e (B) depois da calibração. 
dos poluentes determinadas no referido período (Tabela 7) foram utilizadas no modelo na função EMC, referentes ao coeficiente $\mathrm{K}_{\mathrm{W}}$

Também para o processo de lavagem, as sub-bacias D1, D3, D4 e D5 apresentaram as maiores cargas de matéria orgânica e FT. Entretanto, nas sub-bacias mencionadas, onde o sistema de drenagem recebe descargas contínuas de águas residuárias, as contribuições advindas dos deflúvios superficiais atuam diluindo a carga de esgoto recebida pelo canal.

Righetto, Gomes e Freitas (2017), ao avaliar o potencial poluidor dos deflúvios em uma bacia de Natal, Rio Grande do Norte, encontraram valores similares ao deste trabalho. Outros pesquisadores, avaliando a modelagem da qualidade da água em bacias urbanas, em regiões onde os serviços de saneamento básico não são totalizados, deparam-se com a mesma situação.

Após a simulação, os erros de continuidade gerados pelo desencadeamento da simulação no SWMM foram verificados para cada

Tabela 7 - Valores de concentração média dos poluentes em mg. $\mathrm{L}^{-1}$.

\begin{tabular}{l|c|c|c}
\multirow{2}{*}{ Sub-bacia } & \multicolumn{3}{|c}{$\mathrm{K}_{\mathrm{w}}$} \\
\cline { 2 - 4 } D1 & DBO & DQO & $\mathrm{FT}$ \\
\hline D2 & 240,25 & 434,1 & 6,5 \\
\hline D3 e D4 & 46,1 & 176,6 & 1,5 \\
\hline D5 & 172,4 & 363,7 & 5,1 \\
\hline D6 & 312 & 533,6 & 7,7 \\
\hline D7 a D9 & 86,7 & 239 & 3,3 \\
\hline D10 a D13 & 113,8 & 308,1 & 4,4 \\
\hline
\end{tabular}

$\mathrm{K}_{\text {: }}$ concentração de poluente lixiviado em unidades de massa por volume; DBO: demanda bioquímica de oxigênio; DQO: demanda química de oxigênio; FT: fósforo total. variável simulada. Em todas as simulações, o erro percentual da DBO variou entre 0,35 e $0,65 \%$, da DQO entre 0,29 e $0,66 \%$ e do FT entre 0,23 e $0,66 \%$, sendo todos os valores inferiores a $1 \%$, indicando, assim, um valor aceitável para a simulação, muito abaixo do valor limite de $10 \%$.

\section{Cenários simulados}

Por meio das cargas acumuladas no início e no fim de cada evento simulado com duração de 15 horas (Tabela 8), pode ser observado o efeito no número de dias antecedentes sem chuva na quantidade de quilogramas de poluente acumulado. Para o evento medido do dia 08 de junho $(10,6 \mathrm{~mm})$ houve aumento de $126,58 \%$ na quantidade de DBO acumulada entre 3 e 15 dias, para DQO e FT o aumento foi de $126,10 \%$. Para as precipitações com TR de 10 e 25 anos, o aumento para DBO, DQO e FT foi de aproximadamente 119\%.

Righetto, Gomes e Freitas (2017) afirmam que um maior número de dias secos pode resultar em maior concentração de poluentes depositados sobre a superfície da bacia. Os autores mostraram que cerca de $50 \%$ da variação das concentrações de DQO foi explicada pela alteração nos valores de dias secos antecedentes, ao passo que para as concentrações de FT a alteração explica cerca de $45 \%$ da variação desse parâmetro.

Por ter uma extensa área de contribuição, cerca de $24 \mathrm{~km}^{2}$, e por apresentar pontos de despejo irregular de águas residuárias, as concentrações de poluentes na área de estudo desta pesquisa são muito elevadas. Por meio da análise percentual da diferença entre a carga de poluentes inicial e final, observa-se que após a chuva de 10,6 mm, $57,5 \%$ da carga de DBO foi lixiviada pelo escoamento para o cenário de três dias sem chuva. Já para 15 dias, como o acúmulo é maior, a quantidade de carga de DBO lixiviada pela mesma chuva caiu para

Tabela 8 - Carga de poluentes no início e no fim dos eventos simulados.

\begin{tabular}{|c|c|c|c|c|c|c|c|}
\hline \multirow{3}{*}{ Evento } & \multirow{3}{*}{ Dias sem chuva } & \multicolumn{6}{|c|}{ Carga (kg) } \\
\hline & & \multicolumn{2}{|c|}{ DBO } & \multicolumn{2}{|c|}{ DQO } & \multicolumn{2}{|c|}{$\mathrm{FT}$} \\
\hline & & Inicial & Final & Inicial & Final & Inicial & Final \\
\hline \multirow{2}{*}{$10,6 \mathrm{~mm}$} & 3 & 17.101 & 7.268 & 37.129 & 14.874 & 528 & 211 \\
\hline & 15 & 38.748 & 27.935 & 83.952 & 59.035 & 1.194 & 839 \\
\hline \multicolumn{2}{|l|}{$\%$ de aumento } & 126,58 & & 126,11 & & 126,10 & \\
\hline \multirow{2}{*}{$\begin{array}{l}\mathrm{TR}=10 \text { anos } \\
100,4 \mathrm{~mm}\end{array}$} & 3 & 18.310 & 2.341 & 39.771 & 5.580 & 566 & 80 \\
\hline & 15 & 40.183 & 3.616 & 87.113 & 9.018 & 1.239 & 129 \\
\hline \multicolumn{2}{|l|}{ \% de aumento } & 119,46 & & 119,04 & & 119,02 & \\
\hline \multirow{2}{*}{$\begin{array}{l}\mathrm{TR}=25 \text { anos } \\
123,6 \mathrm{~mm}\end{array}$} & 3 & 18.299 & 2.270 & 39.754 & 5.402 & 565 & 77 \\
\hline & 15 & 40.173 & 3.518 & 87.097 & 8.774 & 1.239 & 125 \\
\hline \multicolumn{2}{|l|}{$\%$ de aumento } & 119,53 & & 119,09 & & 119,07 & \\
\hline
\end{tabular}

DBO: demanda bioquímica de oxigênio; DQO: demanda química de oxigênio; FT: fósforo total; TR: tempo de retorno. 
27,9\%, ou seja, a chuva de 10,6 mm não foi suficiente para realizar uma boa lavagem dos poluentes acumulados durante o intervalo de 15 dias. Para um maior número de dias secos, seria necessária uma precipitação de grande intensidade para lixiviar uma maior quantidade de carga acumulada. Para DQO e FT, a carga lixiviada foi de 60,0\% para o intervalo de 3 dias e de $29,7 \%$ para o de 15 dias.

As chuvas com TR de 10 e 25 anos têm maior intensidade que a do evento de 10,6 mm. Logo, a quantidade lixiviada para os dois períodos aumenta, sendo obtida $87 \%$ de carga lixiviada com 3 dias sem chuva e 91\% com 15 dias, tanto para DBO quanto para DQO e FT. Temprano et al. (2006) determinaram que 65, 57 e 54\% das cargas poluidoras de DQO, sólidos suspensos (SS) e nitrogênio total Kjeldahl (NTK), respectivamente, foram varridas pelos primeiros $30 \%$ do volume nos eventos pluviométricos utilizados na calibração do modelo.

Pelas Figuras 6 e 7, que apresentam a comparação entre a qualidade do escoamento gerado em cada sub-bacia no início e no final da simulação feita para os eventos de 10,6 e 123,6 mm (TR = 25 anos) por meio de mapas de concentração, fica explícito o comportamento da lixiviação dos poluentes por meio de cada volume precipitado. No evento com $10,6 \mathrm{~mm}$, apenas quatro sub-bacias apresentaram concentrações de DBO menores que $50 \mathrm{mg} . \mathrm{L}^{-1}$, ao mesmo tempo que no final do evento de 123,6 mm todas as sub-bacias apresentaram coloração azul-escura (valores abaixo de $50 \mathrm{mg} \cdot \mathrm{L}^{-1}$ ). O mesmo comportamento é observado para as variáveis DQO e FT.

Chen et al. (2018), sob diferentes condições de chuva, verificaram que o valor máximo dos poluentes apareceu nos estágios inicial e médio da chuva, enquanto diminuiu gradualmente com o aumento das chuvas. A concentração de poluentes mostra uma tendência de queda durante o processo de chuvas.

As Figuras 8 e 9 exibem o comportamento da DBO nos trechos do Canal do Prado ao longo das 15 horas simuladas para cada evento. Observando o comportamento da concentração do poluente ao longo do tempo, percebe-se que não ocorre redução na concentração durante as 15 horas do evento simulado. Após 1 hora (na 16 hora de simulação), a concentração dos poluentes começa a diminuir. O comportamento das curvas para DBO e FT é o mesmo mostrado nas Figuras 8 e 9, variando apenas as concentrações referentes a cada poluente.

Na simulação do evento de 123,6 mm (Figura 9), observa-se que praticamente toda a concentração de poluente é lixiviada pela chuva em aproximadamente 7 horas de duração, sendo apenas os trechos 7 e 8 os que não apresentaram valor nulo ao final da simulação, com concentrações de 0,27 e 1,23 mg. $\mathrm{L}^{-1}$, respectivamente. Os trechos 1, 2, 3 e 4 tiveram toda sua carga lixiviada nas primeiras 3 horas do evento e o trecho 5 depois de 5 horas.

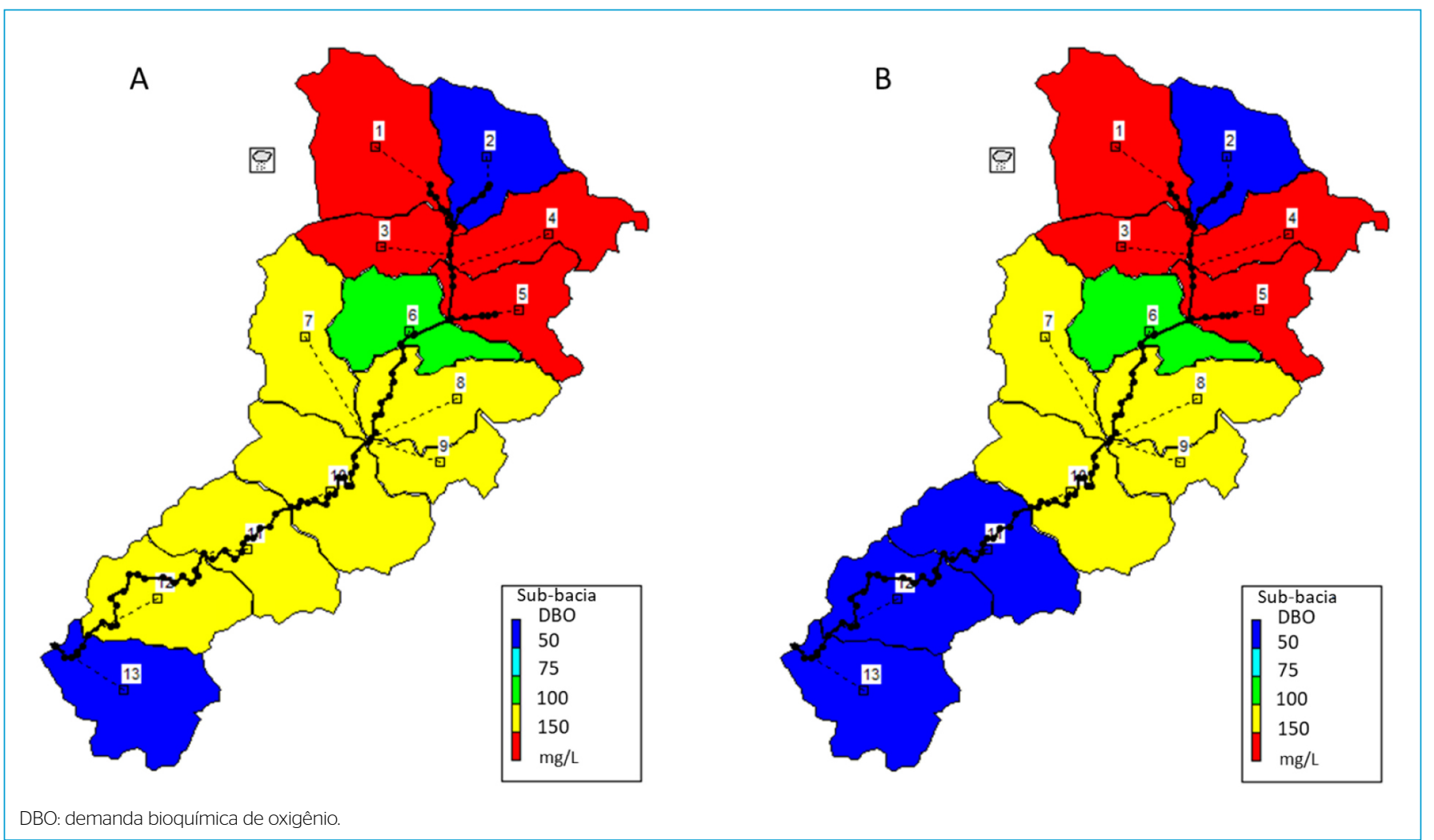

Figura 6 - Mapa da concentração de demanda bioquímica de oxigênio no escoamento gerado nas sub-bacias para o evento de 10,6 mm: (A) 3h30min após o início da simulação; e (B) no final do evento. 

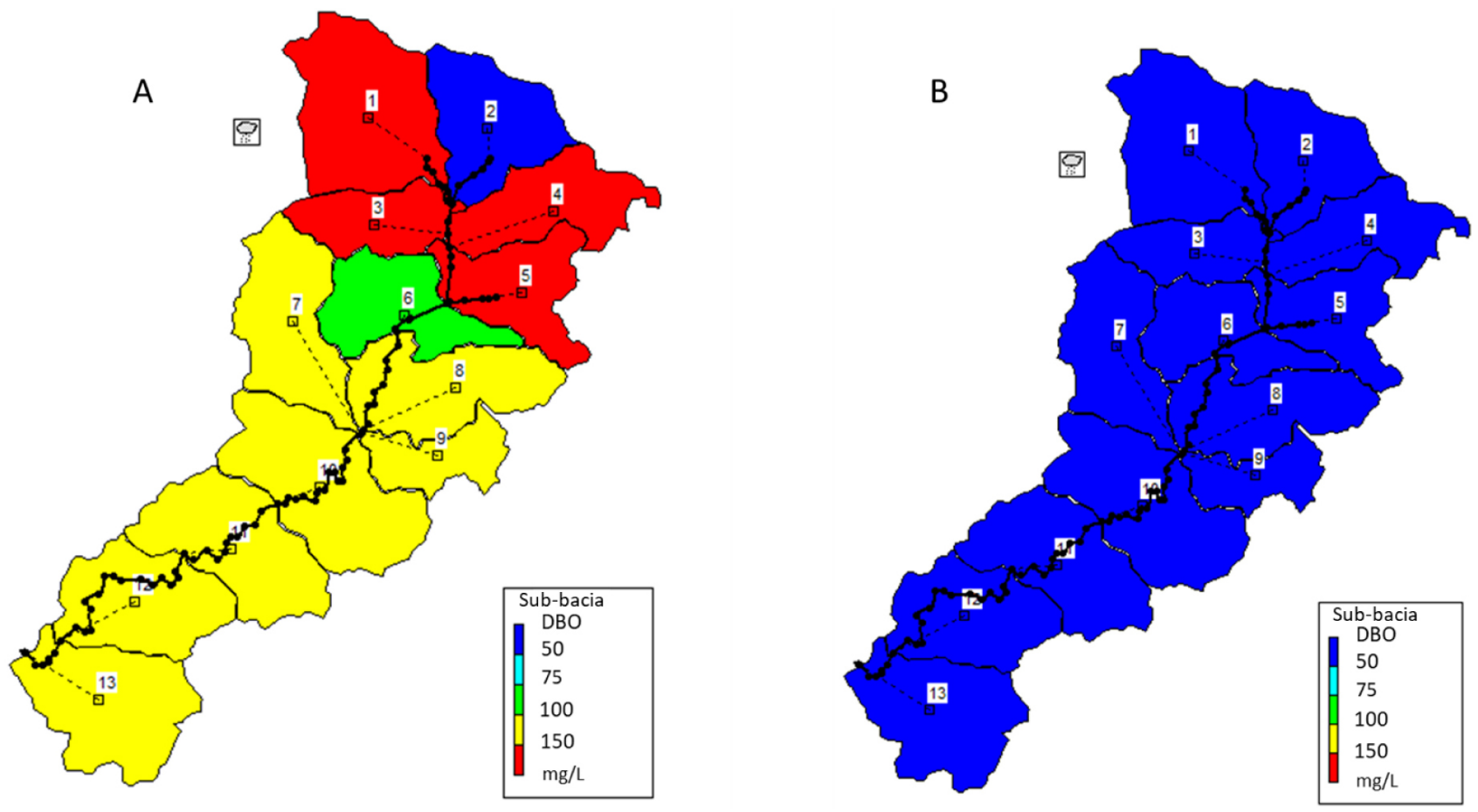

DBO: demanda bioquímica de oxigênio.

Figura 7 - Mapa da concentração de demanda bioquímica de oxigênio no escoamento gerado nas sub-bacias para o evento de 123,6 mm: (A) 1h15min após o início da simulação; e (B) no final do evento.

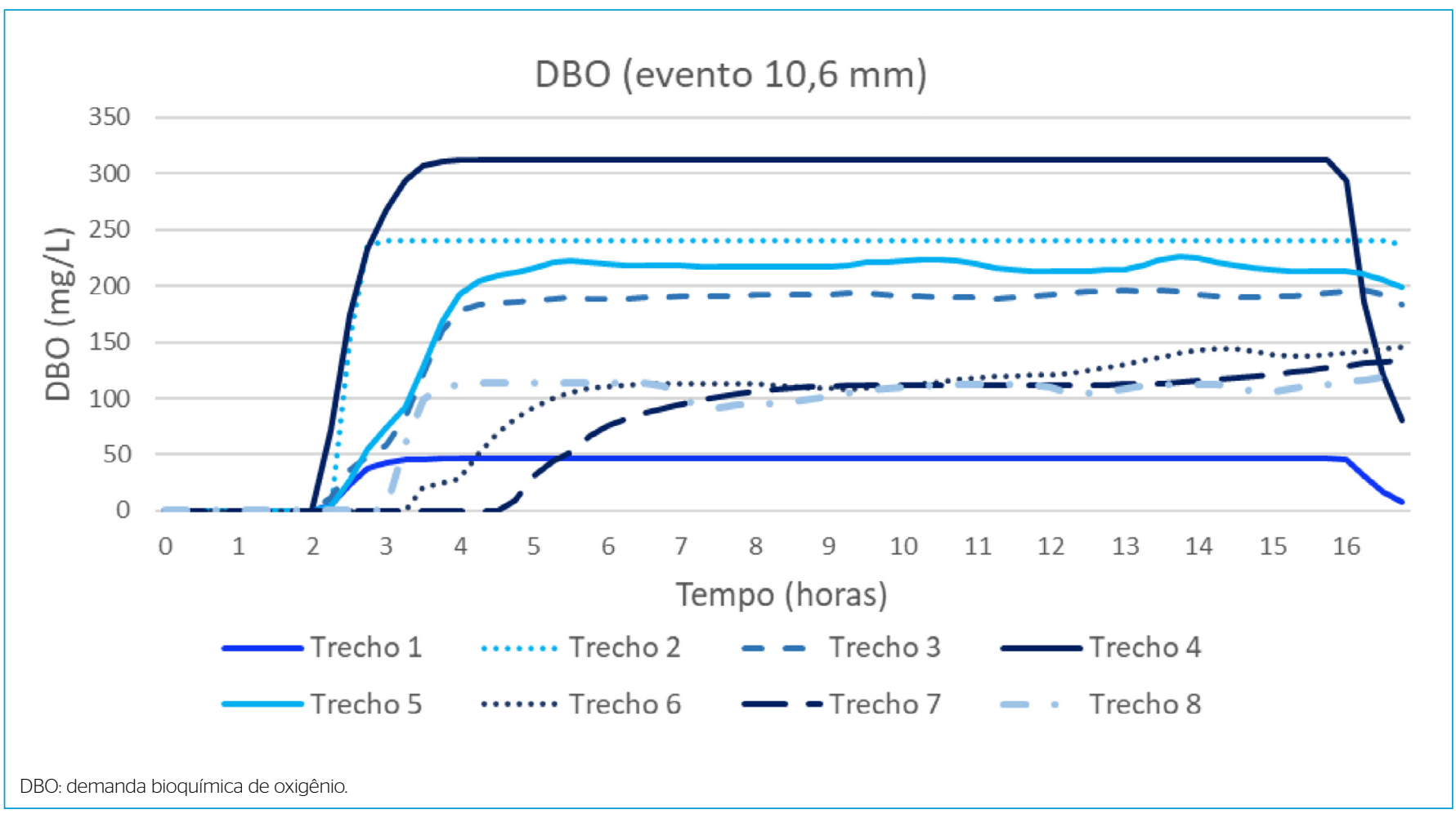

Figura 8 - Gráfico da concentração de demanda bioquímica de oxigênio nos trechos do canal para o evento de 10,6 mm. 


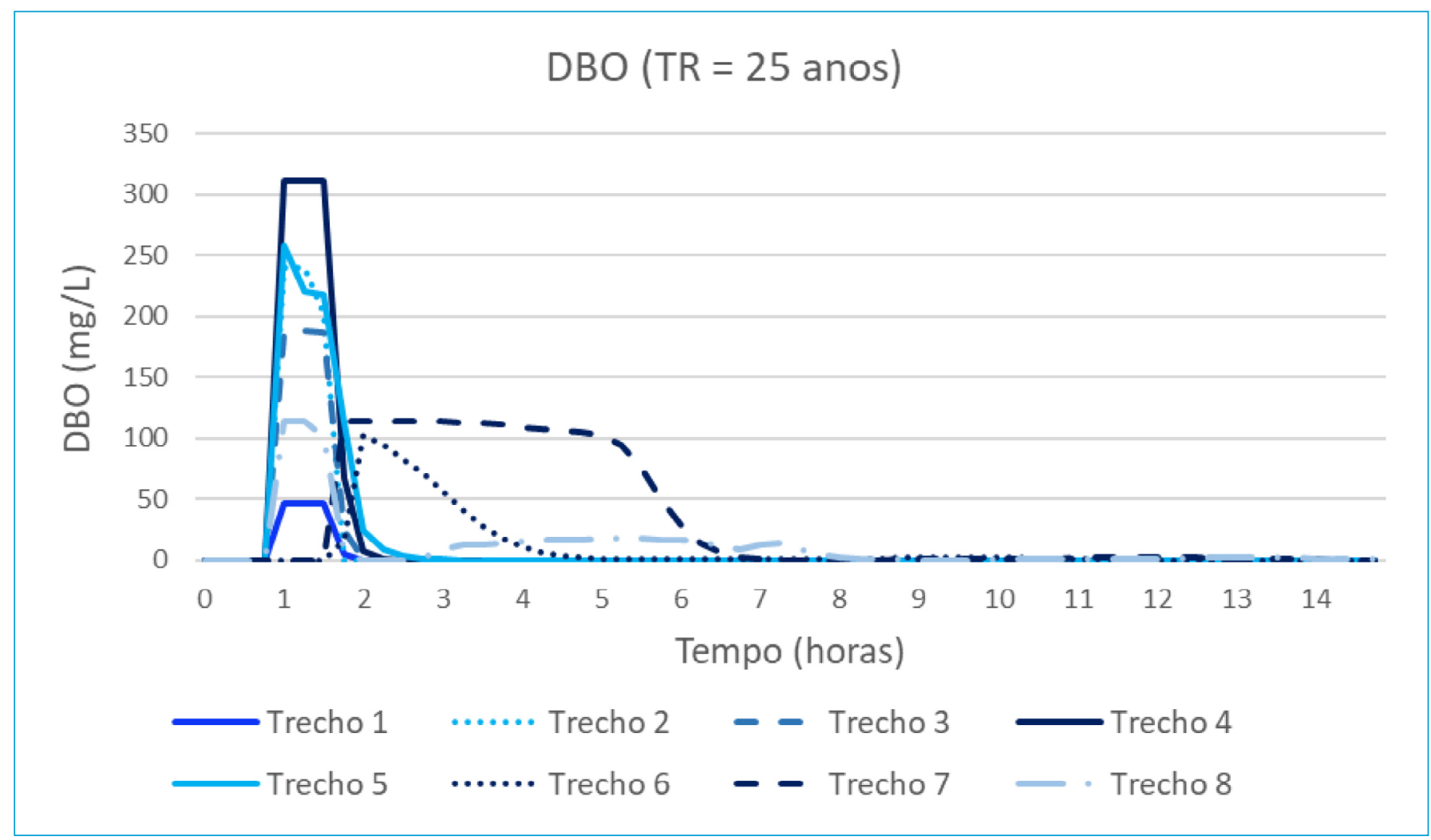

Figura 9 - Gráfico da concentração de demanda bioquímica de oxigênio nos trechos do canal para o evento de 123,6 mm.

\section{CONCLUSÕES}

A aplicação do modelo SWMM para a simulação chuva/vazão foi eficaz. O modelo leva em consideração parâmetros como infiltração, área, largura, capacidade de armazenamento em depressões, entre outros, que têm grande influência na vazão final gerada, e que, por serem muitos, acabam dificultando o processo de calibração. Entretanto, pode-se concluir que o programa respondeu bem a simulação dos fenômenos hidráulicos e hidrológicos que ocorrem na bacia e nas galerias de drenagem pluvial.

Considerando os resultados obtidos a partir dos cenários, conclui-se que a intensidade da precipitação apresenta maior influência na redução das cargas acumuladas superficialmente na bacia e na concentração do escoamento gerado, visto que a carga acumulada não apresentou aumento significativo para as diferentes intensidades simuladas.

\section{REFERÊNCIAS}

AMERICAN PUBLIC HEALTH ASSOCIATION (APHA); AMERICAN WATER WORKS ASSOCIATION (AWWA); WATER POLLUTION CONTROL FACILITIES (WEF). (2O12) Standard Methods for the Examination of Water and Wastewater. 21a ed. Washington, D.C.: APHA.

BRASIL. (2010) Decreto no 7.217, de 21 de junho de 2010: regulamenta a Lei Federal n 11.445, de 5 de janeiro de 2007 e estabelece diretrizes nacionais para o saneamento básico, e dá outras providencias. Brasil.

CABRAL JÚNIOR, J.B. (2014) Comparação de dados diários de evapotranpiração de referência estimados pelos métodos de
Penman-Monteith e tanque classe A, para Campina Grande- PB. Trabalho de conclusão de curso (Especialização em GeoAmbiência e Recursos Hídricos do Semiárido) - Universidade Estadual da Paraíba, Campina Grande.

CAMPINA GRANDE. (2015) Relatório Técnico do Plano Municipal de Saneamento Básico de Campina Grande. Campina Grande.

CHEN, X.; SHE, J.; LAI, C.; CHEN, L.; WANG, Y.; ZHONG, K.; CHEN, J.; WANG, Z. (2O18) Analysis on Water Quality Characteristics of Typical Black and Stinking River in Chengdu City by SWMM. Hydrology, v. 6, n. 4, p. 100-106. http://doi.org/10.11648/j.hyd.20180604.11 
FERREIRA, L.C.A. (2008) Variação da qualidade da água do escoamento superficial de duas bacias de drenagem de Natal / RN- Brasil. Dissertação (Mestrado em Engenharia Sanitária) Universidade Federal do Rio Grande do Norte, Natal.

HENRIQUES, J.A. (2014) Distribuição da contaminação fecal em águas de drenagem afluentes do canal do prado, Campina Grande$P B$. Dissertação (Mestrado em Engenharia Civil e Ambiental) Universidade Federal de Campina Grande, Campina Grande.

INSTITUTO BRASILEIRO DE GEOGRAFIA E ESTATISTICA (IBGE). (2018) Cidades. Rio de Janeiro: IBGE. Disponível em: <http://cidades. ibge.gov.br/brasil/pb/campina-grande/panorama>. Acesso em: 12 out. 2017

METHODS, H.; DIETRICH, K. (2007) Stormwater Conveyance Modelling and Design. Bentley: Bentley Institute Press.

NÓBREGA, P.V.M. (2012) Análise do sistema de drenagem de Campina Grande/PB para proteção de áreas de risco de inundação. Dissertação (Mestrado em Engenharia Civil e Ambiental) Universidade Federal de Campina Grande, Campina Grande.

PAIXÃO, F.J.R.; ANDRADE, A.R.S.; AZEVEDO, C.A.V.; COSTA, T.L.; GUERRA, H.O.C. (2009) Ajuste da curva de infiltração por meio de diferentes modelos empíricos. Pesquisa Aplicada \& Agrotecnologia, v. 2, n. 1, p. 108-112

PETRUCCI, G.; RODRIGUEZ, F.; DEROUBAIX, J.E.; TASSIN, B. (2014) Linking the management of urban watersheds with the impacts on the receiving water bodies: the use of flow duration curves. Water Science Technology, v. 70, n. 1, p. 127-135. http://doi.org/10.13140/2.1.4663.5841

RIGHETTO, A.M.; GOMES, K.M.; FREITAS, F.R.S. (2017) Poluição difusa nas águas pluviais de uma bacia de drenagem urbana. Engenharia Sanitária e Ambiental, v. 22, n. 6, p. 1109-1120. http:// dx.doi.org/10.1590/s1413-41522017162357

ROSSMAN, L.A. (2015) Storm Water Management Model, User's Manual Version 5.1. Cincinnati: U.S. Environmental Protection Agency.

ROSSMAN, L.A.; HUBER, W.C. (2016) Storm Water Management Model, Reference Manual Volume III - Water Quality. Cincinnati: U.S. Environmental Protection Agency.

SANTOS, A.N.C. (2011) Influência da precipitação no rendimento agrícola do feijão (Phaseolus vulgaris L.) e algodão herbáceo
(Gossypium hirsutum L.) em Campina Grande - PB. Dissertação (Mestrado em Metereologia) - Universidade Federal de Campina Grande, Campina Grande.

SANTOS, K.A.; RUFINO, I.A.A.; BARROS FILHO, M.N.M. (2O17) Impactos da ocupação urbana na permeabilidade do solo: o caso de uma área de urbanização consolidada em Campina Grande PB. Engenharia Sanitária e Ambiental, v. 22, n. 5, p. 943-952. https:// doi.org/10.1590/s1413-41522016146661

SILVA, M.M.P.; OLIVEIRA, N.F.; CAVALCANTI, N.B. (1981) Probabilidade de ocorrência de dias secos e chuvosos. Boletim Instituto Nacional de Meteorologia, v. 146, p. 51-90.

SONG, C.; LIU, X.; SONG, Y.; LIU, R.; GAO, H.; HAN, L.; PENG, J. (2017) Key blackening and stinking pollutants in Dongsha River of Beijing: Spatial distribution and source identification. Journal of Environmental Management, v. 200, p. 335-346. https://doi. org/10.1016/j.jenvman.2017.05.088

TEMPRANO, J.; ARANGO, O.; CAGIAO, J.; SUÁREZ, J.; TEJERO, I. (2006) Stormwater quality calibration by SWMM: A case study in Northern Spain. Water SA, v. 32, n. 1, p. 55-63. https://doi.org/10.4314/ wsa.v32i1.5240

TSUYUGUCHI, B.B. (2015) Macrodrenagem e ocupação do solo no municipio de Campina Grande: Caracterização, simulação e análises sistêmicas. Dissertação (Mestrado em Engenharia Civil e Ambiental) - Universidade Federal de Campina Grande, Campina Grande.

TUOMELA, C:; SILLANPÄÄ, N.; KOIVUSALO, H. (2019) Assessment of stormwater pollutant loads and source area contributions with storm water management model (SWMM). Journal of Environmental Management, v. 233, p. 719-727. https://doi. org/10.1016/j.jenvman.2018.12.061

ZAFFANI, A.G. (2012) Poluição Difusa da Drenagem Urbana com Base Ecohidrológica: Diagnóstico Atual e Cenários de Longo Prazo em Bacias Urbanas de São Carlos, SP. Dissertação (Mestrado em Engenharia Hidráulica e Saneamento) - Escola de Engenharia de São Carlos, Universidade de São Paulo, São Carlos.

ZHU, H.; XU, Y.; YAN, B.; GUAN, J. (2012) Snowmelt runoff: a new focus of urban nonpoint source pollution. International Journal of Environmental Research and Public Health, v. 9, n. 12, p. 4333-4345. https://dx.doi.org/10.3390\%2Fijerph9124333 